Case Report

\title{
MICROFILARIA IN PERICARDIAL EFFUSION COEXISTING WITH SPINDLE CELL THYMOMA-A RARE CASE REPORT
}

\author{
Harish S. Permi', Samaga B.N. ${ }^{2}$, Subramanyam K.. ${ }^{3}$ Jayaprakash Shetty K. ${ }^{1}$, Teerthanath S. ${ }^{1}$, \\ Vidya Baikunje ${ }^{4}$, Kurian Ninan ${ }^{4}$ \\ ${ }^{1}$ Assistant professor, Dept. of Pathology, ${ }^{2}$ Professor, Dept. of M edicine, ${ }^{3}$ Chief interventional cardiologist and Head, \\ Dept. of Cardiology, ${ }^{1}$ Professor \& Head of Dept., Dept. of Pathology, ${ }^{1}$ Professor, Department of Pathology, ${ }^{1}$ Professor, \\ Radio diagnosis and Imaging, ${ }^{1}$ Assistant professor, Radio diagnosis and Imaging \\ K S Hegde M edical Academy, Nitte University, Deralakatte, M angalore, Karnataka, India.
}

\section{Correspondence:}

Harish S. Permi,

Asst. Professor, Dept of Pathology, K.S. Hegde M edical Academy, Nitte University, Deralakatte, Mangalore ,KARNATAKA (state), INDIA (country).

M obile : 9964131827 E-mail : drharish01@gmail.com

\begin{abstract}
:
Lymphatic filariasis is common in tropical countries and is endemic in South India. Filariasis presenting with pericardial effusion is rare, coexisting with spindle cell thymoma is still very rare. We report a case of a 53-year-old male who was admitted to cardiac intensive care unit with severe breathless since two days. Cardiac Echocardiogram showed massive pericardial effusion with cardiac tamponade and large anterior mediastinal mass. Pericardial fluid aspiration drained 1.5 litres of hemorrhagic fluid. Cytology examination revealed microfilaria of Wutchereria bancrofti. FNAC and trucut biopsy from anterior mediastinal mass showed features of spindle cell thymoma. He was treated with diethyl carbamazine thrice daily for one month. He refused for excision of thymoma. This case report is a rare coexistence of microfilaria in pericardial effusion with spindle cell thymoma. We stress the need to consider filariasis as differential diagnosis in the evaluation of hemorrhagic pericardial effusion especially in endemic areas.
\end{abstract}

Keywords: Pericardial effusion, microfilaria, spindle cell thymoma.

Introduction :

Lymphatic filariasis is a major health problem in India especially in southern states with most infections caused by Wutchereria bancrofti. ${ }^{(1)}$ Filariasis acutely presents with fever, adenolymphangitis, funniculitis, epididymitis or orchitis. Lymphoedema, hydrocele, elephantiasis and chyluria are features of chronic infection. ${ }^{(2)}$ The microfilaria are not just confined to the lymphatic system but also associated with other organs, subcutaneous tissues and serous cavities like pleura and pericardium. ${ }^{(3)} \mathrm{M}$ icrofilaria has been observed as coincidental findings with other inflammatory conditions, primary malignant tumors and in metastatic deposits. ${ }^{(4)}$ Our case was a rare coexistence of microfilaria in pericardial effusion with spindle cell thymoma, which is not described in literature.

\section{Case report:}

A 53 year old male admitted to cardiac intensive care unit with severe breathlessness since two days. He complained of cough, breathlessness on exertion since one month and generalised weakness since 15 days. On examination he was severely dyspnoeic and had pulsus paradoxus. Cardiac Echocardiogram showed massive pericardial effusion with cardiac tamponade and large anterior mediastinal mass. CT scan thorax showed large heterogeneously enhancing anterior mediastinal mass lesion with pericardial effusion. (Figure 1) Possibility of malignant effusion from anterior mediastinal tumor was considered. Pericardiocentesis was done and $1500 \mathrm{ml}$ of haemorrhagic fluid was collected. A continuous drain was put. Cytology showed plenty of neutrophils, occasional eosinophils, RBCs and microfilaria of wutchereria bancrofti. (Figure 2) There was no evidence of malignant cells.

Haematological and biochemical tests were within normal limits.HIV and HBsAg were nonreactive. Adenosine deaminase (ADA) level was 62 units/L. Patient was started on diethylcarbamazine (DEC) $100 \mathrm{mg}$ thrice a day immediately. The patient improved rapidly by next day and effusion was grossly reduced by the third day and the drain 
was removed. DEC was continued for another three weeks. The cardiac silhouette returned to normal.CT guided fine needle aspiration of mediastinal mass showed clusters of spindle cells having moderate amount of cytoplasm with bland nucleus and lymphoid cells in the background. (Figure 3) Spindle cell thymoma was considered. Tru cut biopsy confirmed the cytology diagnosis. (Figure 4) Repeat Echocardiogram after one month showed no pericardial effusion. Surgical excision of mediastinal tumor was planned but patient was not willing for surgery.

\section{Discussion :}

Lymphatic filariasis is a common public health problem of tropical and subtropical countries including parts of Latin America, Sub-Saharan Africa and Southeast Asia. It is estimated that approximately 600 million people are living in areas endemic for lymphatic filariasis in Southeast Asia

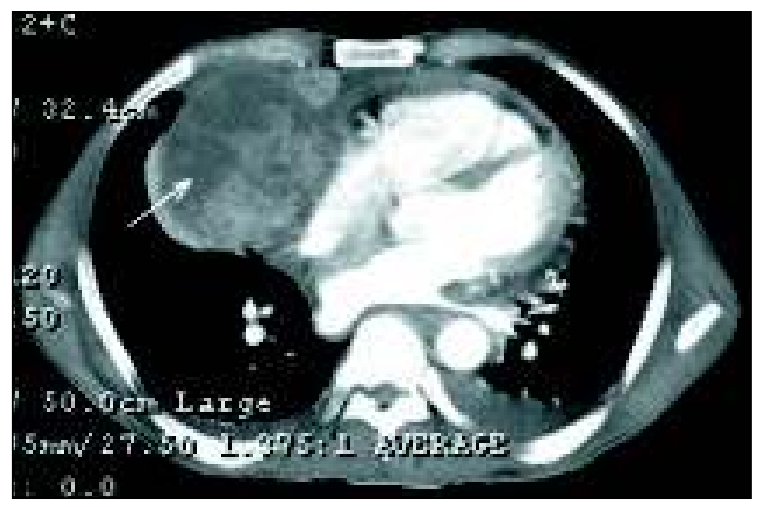

Figure 1: Contrast-enhanced coronal section of CT scan thorax showing heterogeneously enhancing anterior mediastinal mass and pericardial effusion.

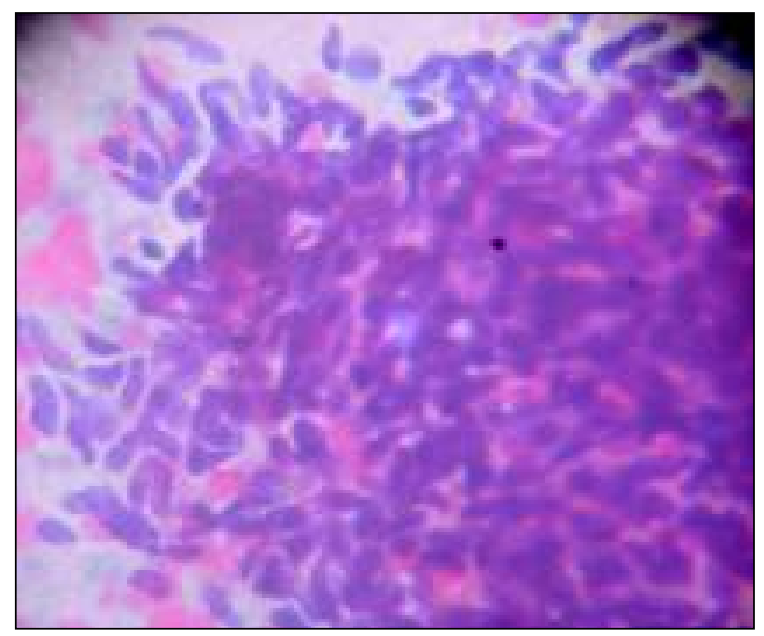

Figure 3: FNAC smear of spindle cell thymoma showing clusters of benign spindle and scanty lymphoid cells. (PAP stain, 400x)
Region. There are approximately 60 million people infected in the region and approximately 31 million people have clinical manifestation of the disease. ${ }^{(5)}$ It is transmitted by the Culex mosquito and is caused by two closely related nematodes, W. bancrofti and Brugia malayi, which are responsible for $90 \%$ and $10 \%$ of the cases, respectively. ${ }^{(5)}$ Microfilaria have been identified in samples submitted for cytological examination, such as aspirated material from lymph node, breast lump, cutaneous swellings and also from bone marrow, bronchial aspirate, nipple discharge, ascitic, pleural and pericardial fluid, ovarian cyst fluid and cervicovaginal smears. ${ }^{(6)}$ Although microfilarias in unusual sites are considered incidental findings, the association of microfilaria with debilitating conditions suggests that it may be an opportunistic infection or it may be coincidental with various neoplasm. However pericardial effusion is an uncommon manifestation. The portal of entry of

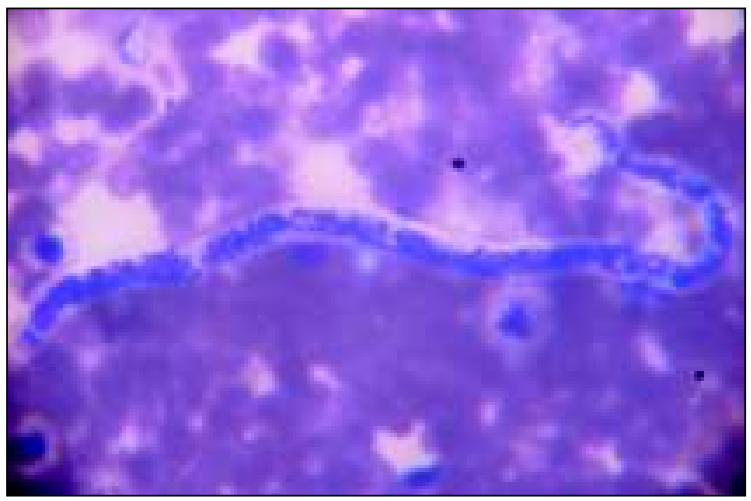

Figure 2: Pericardial fluid cytology smear showing microfilaria in a hemorrhagic background with occasional neutrophils. (Leishman stain, 400X)

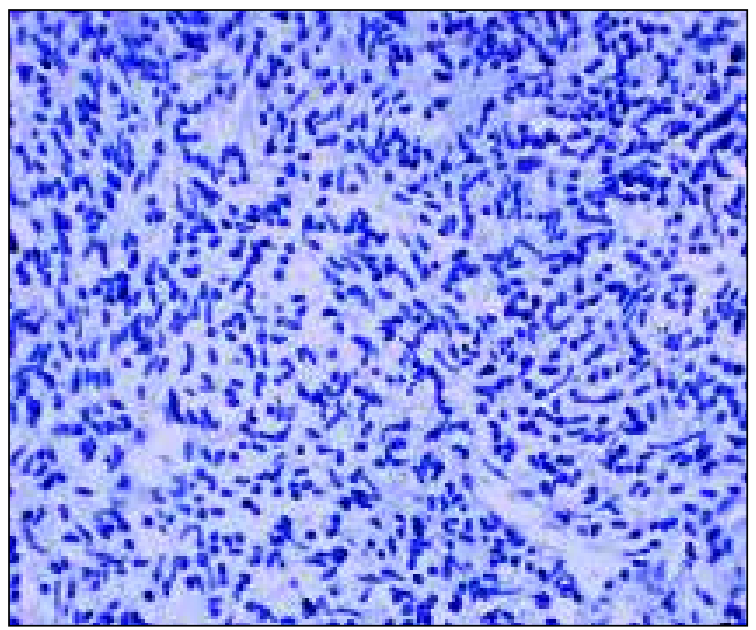

Figure 4: Tru-cut biopsy showing spindle cell thymoma. (Haematoxylin and Eosin, 400X) 
microfilaria to the pericardial space is still a speculation. It might have lodged itself through blood stream subsequent to development of pericarditis. As microfilaria is capable of penetrating the tissues of the vector, they can freely move in and out of small, delicate blood, and lymphatic capillaries and tissues of the vertebrate host. ${ }^{(3)}$ Our case patient presented with severe breathlessness and mass in the anterior mediastinum where clinically malignant effusion was suspected and thoracocentesis was done. The aspirated hemorrhagic fluid demonstrated microfilaria; he

\section{References:}

1) Adhish Basu, Sarath Chandra Sistla, Surendra Kumar Verma, SJagdish. Lymphadenovarix in the axilla - an unusual presentation of filariasis. Filaria Journal, 2006; 9, 1-5.

2) Prashant L Patil, Harsha R Salkar, Shekhar S Godeshwar, Jayant $P$ Gawand. Parasites (Filaria and Strongyloides) in malignant pleural effusion. Indian J M ed Sci, 2005, 59, 10,455-6.

3) KPrasanthi, KNagamani, N K Saxena. Unresolving pericarditis: Suspect filariasis in the tropics. Indian Journal of Medical M icrobiology; 2010, $28,73-5$ was treated with DEC thrice daily for one month with complete resolution of pericardial effusion. Later excision of spindle cell thymoma was planned but patient refused for surgery.

\section{Conclusion}

Our case report is very rare coexistence of microfilaria in pericardial effusion with spindle cell thymoma and we stress the need to consider filariasis as one of the differential diagnosis of hemorrhagic pericardial effusion, especially in endemic areas.

4) Sachin S Kolte, Rahul N Satarkar, Pratibha M Mane. Microfilaria concomitant with metastatic deposits of adenocarcinoma in lymph node fine needle aspiration cytology: A chance finding. J Cytol. 2010 April; 27(2): 78-80.

5) Chowdhary M, Langer S, Aggarwal M , Agarwal C. M icrofilaria in thyroid gland nodule. IndianJ Pathol Microbiol 2008; 51:94-6.

6) Singh SK, Pujani M, Pujani M. Microfilaria in malignant pleural effusion: An unusual association. Indian J Med Microbiol 2010; 28:392-4. 